\title{
A TEORIA DA AÇÃO COMUNICATIVA COMO REFERENCIAL TEÓRICO AO ESTUDO DA INTERDISCIPLINARIDADE
}

Mônica Bragaglia*

SÍNTESE - A interdisciplinaridade constitui-se, atualmente, como uma das posturas imprescindíveis de existência nas intervençōes realizadas junto às demandas que se colocam. Face a esta constatação é evidente que também a postura profissional do assistente social seja orientada por esta perspectiva para que desta forma possa inserir-se junto às demais categorias profissionais $\mathrm{e}$, mesmo, junto à sociedade em geral de forma mais efetiva. Investigar a utilização da Teoria da Ação Comunicativa de Jürgen Habermas como referencial de análise da configuração da interdisciplinaridade nas açōes do Serviço Social, constitui-se no tema central deste texto.
ABSTRACT - Nowadays the interdisciplinarity constitutes one of the indispensable postures in the practicable interventions in view of the reality. In face of this evidence, it is visible that the social worker's professional posture be orientated by this perspective in order to insert him into the order professional categories and the society. The inquiry of the utilization of the Communication Action Theory of Jürgen Habermas becomes the analysis' reference of the interdisciplinarity configuration in the social work actions and is the central topic of this text.

Inicialmente é importante esclarecer que nosso contato com a teoria habermasiana iniciou-se há pouco mais de um ano o que implica necessariamente uma caminhada de apropriação teórica e, evidentemente, ainda permanecem muitas lacunas nesse caminho. Contudo, nesse momento nosso objetivo é demonstrar como tem se dado essa apropriação teórica e sua materialização no que se refere a aspectos especificos da investigação que estamos realizando.

Nesse sentido, é pertinente ressaltar que falar em utilização da teoria habermasiana na investigação científica requer, impreterivelmente, retomar algumas premissas em torno dessa teoria bem como em torno da própria problemática de pesquisa na qual a mesma está sendo aplicada.

Tendo como busca principal de sua proposta teórica a emancipação dos sujeitos e a democratização da sociedade, Habermas apresenta uma interação entre uma teoria crítica da sociedade e teorias emancipatórias do sujeito como caminho viável na busca de uma sociedade democrática constituída de indivíduos maduros.

* Universidade Luterana do Brasil, ULBRA.

\begin{tabular}{|l|l|l|l|l|l|}
\hline VERITAS & Porto Alegre & v. 41 & $\mathrm{n}^{\circ} 162$ & Junho 1996 & p. 299-306 \\
\hline
\end{tabular}


Para uma aplicação e leitura de sociedade sua proposta parece-nos bastante, como nos disse o professor Stein em palestra proferida alguns dias atrás, "arrojada para ser testada pela empiria"; no entanto, parece-nos também muito propícia à sua utilização em instâncias constituintes dessa sociedade maior, ou mesmo na busca da sociedade almejada por Habermas.

Nosso estudo subsidia-se principalmente pela Teoria da Ação Comunicativa posta pelo autor e na aplicação da mesma em um dos movimentos da sociedade atual face à complexa crise vivenciada: a interdisciplinaridade.

Falar em interdisciplinaridade, embora pareça-nos hoje tão familiar e próximo, implica lembrar nebulosidade, pertinência, construção, vivacidade. Isso porque a própria interdisciplinaridade embora muito discutida nos tempos atuais, apresenta uma ausência bastante grande de experiências efetivamente constituídas e, conseqüentemente, apresenta certa obscuridade no que se refere à sua própria conceituação.

Frente a esta situação, permeada de lacunas e equivocos, é que consideramos pertinente e relevante o estudo em torno do tema interdisciplinaridade. $O$ interesse de nosso estudo amplia-se quando almejamos captar em que medida essa perspectiva está sendo referência ao Serviço Social enquanto categoria profissional, inserida na realidade com uma ação interveniente sobre a mesma.

Sendo nossa pesquisa realizada na área de metodologias do Serviço Social estamos buscando clarificar como a intervenção do assistente social tem se articulado à perspectiva interdisciplinar, no Rio Grande do Sul, no período entre 1984 e 1994.

Entretanto, captar a configuração da perspectiva interdisciplinar no Serviço Social conduziu-nos, na busca pela construção de um ensaio científico, a uma apropriação teórica que, ao permear e orientar nossa leitura da realidade, pudesse delimitar mais claramente o próprio entendimento de interdisciplinaridade orientador do presente estudo.

Como já referimos anteriormente, a teoria habermasiana pensa o sujeito numa constante interação social argumentativa para construção de uma sociedade democrática e madura. Entretanto, essa interação social, segundo Habermas, fundamenta-șe essencialmente na linguagem e na competência argumentativa dos indivíduos nas relações estabelecidas.

Há de se ponderar e considerar também nossos questionamentos com relação à aplicação prática desses ideais e suas limitações. Por mais que a linguagem, nessa teoria, seja percebida como uma complexidade tal que as palavras significam mais do que apenas manifestações verbais visto que, "quando examinamos o que se deve dizer e quando se deve fazê-lo, que palavras devemos usar em determinadas situações, não estamos examinando simplesmente palavras (ou seus 'significados' ou seja lá o que for), mas sobretudo a realidade sobre a qual falamos ao usar estas palavras - usamos uma consciência mais aguçada das palavras para aguçar nossa percepção dos fenômenos" (Austin, 1979, p. 182), ainda fica questionável a viabilidade de se alcançar uma sociedade democrática via competência discursiva, se a sociedade, tal como é atualmente constituída, não é formada na sua totalidade por indivíduos dotados de tal competência. 
Entretanto, para uma aplicação empírica no que se refere à questão interdisciplinar, a teoria habermasiana, mesmo com seus limites, se apresenta como uma possibilidade bastante frutífera para iluminar e investigar o fenômeno da interdisciplinaridade, visto que a ética discursiva apresenta como aspecto principal a busca de conexões entre diversos elementos visando um consenso racional a ser conquistado através do processo comunicativo.

O consenso entre os mais variados saberes é operacionalizado através de uma troca intersubjetiva. A comunicação aparece então como instrumento de efetivação desse pressuposto. Assim, falar em comunicação supõe a necessidade de um objetivo comum que se concretiza através de um processo ideal de trocas. Nesse sentido, a busca pelo consenso racional implica no processo comunicativo, a existência de alguns princípios orientadores da ação quais sejam: Princípio U (Universalização) e Princípio D (Ética Discursiva).

Considerando as contribuições feitas no decorrer deste curso sobre a Teoria da Ação Comunicativa de Habermas, a retomada das mesmas nesse momento é menos pertinente, e não se constitui como objetivo desse encontro, do que a evidência de sua própria aplicação na investigação científica.

Assim, o entendimento que orienta esse estudo em torno da perspectiva interdisciplinar é o elemento imprescindível de apontarmos nesse momento; interdisciplinaridade está aqui sendo entendida como troca intersubjetiva e argumentativa de saberes entre elementos de uma mesma ou equivalente competência, permeada por uma situação de igualdade de direitos e participação e, ainda, voltada para a busca do consenso racional sobre determinada questão.

Não desconsideramos contribuições de estudiosos reconhecidos em torno do tema, tais como: necessidade de uma atitude de humildade, respeito, disponibilidade, postura interdisciplinar e outros. Entretanto, consideramos esses elementos como pertinentes mas não determinantes na operacionalização da interdisciplinaridade. Nesse sentido é que orientamos nossa apreensão do real a partir do entendimento anteriormente explicitado.

Contudo, para clarificar como a intervenção do assistente social tem se articulado à perspectiva interdisciplinar sendo esta entendida como a troca intersubjetiva e argumentativa de saberes entre elementos de uma mesma ou equivalente competência, permeada por uma situação de igualdade de direitos e participação e, ainda, voltada para a busca do consenso racional sobre determinada questão, foi imprescindivel delimitarmos nosso estudo a partir de um sistema de idéias apriorísticas em torno do problema central proposto, constituindo nossa problemática de estudo.

Nesse sistema, procuramos abarcar as principais categorias norteadoras da pesquisa, quais sejam: troca intersubjetiva, competência argumentativa, situação ideal de fala, consenso racional, bem como as instâncias dentro do Serviço Social que pretendemos analisar.

Assim, as hipóteses que orientaram nossa apreensão da realidade constituiram-se da seguinte forma:

** O Serviço Social, enquanto categoria profissional inserida no mundo da vida que se configura, de forma peculiar, nos dias de hoje, tem um discurso relativamente uniforme que explicita o reconhecimento da importância e o entendimento 
da necessidade de uma ação integrada com base comunicativa, a fim de atingir uma intervenção intersubjetivamente construída. Isso ocorre devido à necessidade premente - advinda das próprias crises vivenciadas pela sociedade como um todo - de uma intervenção que abarque a totalidade do sujeito e da própria realidade, fator imprescindível para o agir profissional efetivo, mais do que uma compreensão efetiva das condições de uma prática na perspectiva interdisciplinar.

** A construção de conhecimento do Serviço Social, no período em estudo, apresenta uma descontinuidade em relação à troca intersubjetiva dos saberes, a partir do que produzido pela comunidade científica. Percebe-se um caráter oscilante na busca de articulação das propostas e ações dessa profissão com a interdisciplinaridade, através das suas próprias realizações - explicitação da relação teóricoprática - quais sejam: seminários, congressos, conferências, publicações e, em especial, nas realizações cientificas que empreende.

** As possibilidades de troca intersubjetiva e de uma ação interdisciplinar, realizada de forma argumentativa num mesmo ou equivalente nível de competência com os demais profissionais, a partir do reconhecimento da situação ideal de fala pelo próprio assistente social, apresentam obstruções. Isso ocorre porque a prática do assistente social tem se caracterizado, em parte, por uma postura isolacionista, restrita e de caráter subalterno perante as outras categorias profissionais com que interage.

** A construção do consenso racional com a efetiva participação do Serviço Social encontra-se fragilizada em função das rupturas existentes na troca comunicativa de saberes e no reconhecimento da igualdade de competência técnica por parte do assistente social. Nesse sentido, verifica-se que a práxis profissional do Serviço Social, que é a expressão de um enfoque teórico, encontra-se permeada de várias ações que caracterizam iniciativas compartimentalizadas e individualistas, visto que o referencial teórico que subsidia tal práxis e que deveria advir do conhecimento acumulado, caracteriza-se ainda por uma forte tendência mais voltada a um caráter de vontade política do que competência teórica.

A partir dessas colocações fica-nos evidente a utilização da teoria habermasiana em algumas instâncias da intervenção teórico-metodológica do Serviço Social.

A nível de discurso da categoria profissional buscamos avaliar, através de questionários enviados pelo correio para uma amostra da categoria no Rio Grande do Sul, o reconhecimento da importância da interdisciplinaridade e o próprio entendimento da mesma, a partir da concepção orientadora do presente estudo no que se refere às respectivas intervenções profissionais dos assistentes sociais respondentes.

Com relação à produção de conhecimento dentro do Serviço Social, buscamos perceber e avaliar como a troca intersubjetiva com as demais áreas do saber está se efetivando dentro de nossa categoria profissional. Para tanto, utilizamo-nos de um estudo das produções mais representativas na última década, de materiais enviados pelos cursos de graduação em Serviço Social do Rio Grande do Sul e órgãos representativos da categoria (CFESS, CRESS, ABESS) a respeito de eventos realizados dentro desta perspectiva e, ainda, as contribuições postas pelos respondentes 
ao questionário enviado para apreensão dos aspectos referentes a hipótese 1 desse estudo.

Finalmente, no que se refere à prática efetivamente realizada pelos assistentes sociais, contatamos com cinco equipes de saúde mental, ditas interdisciplinares do Rio Grande do Sul, para avaliar a existência ou não de uma situação ideal de fala, de uma troca intersubjetiva e argumentativa de saberes e de uma mesma ou equivalente competência com vistas ao consenso racional, com efetiva participação do assistente social.

Para uma melhor visualização da forma como tentamos operacionalizar a Teoria da Ação Comunicativa habermasiana no estudo da configuração da interdisciplinaridade no Serviço Social, apresentamos a seguir o quadro abaixo referente à hipótese 3.

\begin{tabular}{|c|c|c|c|c|c|}
\hline HIPOTESES & CATEGORIAS & CONCEITOS & DIMENSŌES & INDICADORES & $\begin{array}{l}\text { PROCEDI- } \\
\text { MENTOS }\end{array}$ \\
\hline $\begin{array}{l}\text { As possibilidades } \\
\text { de troca intersub- } \\
\text { jetiva e de uma } \\
\text { ação interdiscipli- } \\
\text { nar, realizada de } \\
\text { forma argumenta- } \\
\text { tiva num mesmo } \\
\text { ou equivalente ni- } \\
\text { vel de competên- } \\
\text { cia com os de- } \\
\text { mais profissio- } \\
\text { nais, a partir do } \\
\text { reconhecimento } \\
\text { da situação ideal } \\
\text { de fala pelo pro- } \\
\text { prio assistente so- } \\
\text { cial, apresentam } \\
\text { obstruçöes. Isso } \\
\text { ocorre porque a } \\
\text { prática do assis- } \\
\text { tente social tem } \\
\text { se caracterizado, } \\
\text { em parte, por } \\
\text { uma postura isola- } \\
\text { cionista, restrita e } \\
\text { de caráter subal- } \\
\text { terno perante as } \\
\text { outras categorias } \\
\text { profissionais com } \\
\text { que interage. }\end{array}$ & $\begin{array}{l}\text { troca } \\
\text { intersubjetiva }\end{array}$ & $\begin{array}{l}\text { "Processo } \\
\text { social que se } \\
\text { dá através da } \\
\text { linguagem, } \\
\text { tendo como } \\
\text { referências } \\
\text { certas } \\
\text { estruturas de } \\
\text { racionalidade. } \\
\text { É o tipo de } \\
\text { ação social } \\
\text { voltada para } \\
\text { o } \\
\text { entendimento, } \\
\text { a } \\
\text { compreensão } \\
\text { e o } \\
\text { consenso..." } \\
\text { (SIEBENEICH- } \\
\text { LER, 1989, p. } \\
\text { 94) }\end{array}$ & $\begin{array}{l}\text { - linguagem } \\
\text { (expressão oral } \\
\text { e/ou escrita que } \\
\text { revele } \\
\text { determinada } \\
\text { idéia ou } \\
\text { concepção sobre } \\
\text { o tema em } \\
\text { questão); } \\
\text { - estruturas de } \\
\text { racionalidade } \\
\text { (junção do } \\
\text { trabalho, da } \\
\text { interação e do } \\
\text { entendimento } \\
\text { mútuo; união da } \\
\text { razão ao contexto } \\
\text { total que esta se } \\
\text { encontra } \\
\text { inserida); } \\
\text { - ação social } \\
\text { (açōes } \\
\text { emprendidas na } \\
\text { busca por } \\
\text { determinado } \\
\text { objetivo com } \\
\text { características } \\
\text { totalizantes com } \\
\text { relação à } \\
\text { realidade). }\end{array}$ & $\begin{array}{l}\text { - ações da equipe } \\
\text { interdisciplinar } \\
\text { estudada que revelem } \\
\text { uma troca integrativa } \\
\text { com equipes afins de } \\
\text { outras instituições; } \\
\text { - busca do } \\
\text { entendimento mútuo } \\
\text { da equipe, } \\
\text { vivenciadas através } \\
\text { das discussōes a } \\
\text { respeito de um } \\
\text { determinado assunto } \\
\text { realizadas em } \\
\text { reuniöes; } \\
\text { - participação de } \\
\text { todos os membros da } \\
\text { equipe nas atividades } \\
\text { desenvolvidas, } \\
\text { evidenciada pela } \\
\text { presença ativa de } \\
\text { cada integrante e sua } \\
\text { contribuição no } \\
\text { processo vivenciado; } \\
\text { - troca verbal } \\
\text { argumentativa } \\
\text { concretizada entre os } \\
\text { integrantes da equipe } \\
\text { interdisciplinar } \\
\text { estudada, a respeito } \\
\text { do objeto de } \\
\text { discussão em pauta. }\end{array}$ & $\begin{array}{l}\text { - observaçäo } \\
\text { de reuniöes } \\
\text { da equipe } \\
\text { interdisciplinar } \\
\text { estudada; } \\
\text { - entrevistas } \\
\text { com } \\
\text { integrantes } \\
\text { da equipe; }\end{array}$ \\
\hline
\end{tabular}




\begin{tabular}{|c|c|c|c|c|c|}
\hline HIPÓTESES & CATEGORIAS & CONCEITOS & DIMENSÕES & INDICADORES & $\begin{array}{l}\text { PROCEDI- } \\
\text { MENTOS }\end{array}$ \\
\hline & $\begin{array}{l}\text { equivalente } \\
\text { competência }\end{array}$ & $\begin{array}{l}\text { Disposição } \\
\text { própria de } \\
\text { cada } \\
\text { componente } \\
\text { da equipe } \\
\text { para praticar } \\
\text { a } \\
\text { comunicação } \\
\text { com os } \\
\text { outros } \\
\text { sujeitos } \\
\text { envolvidos no } \\
\text { processo, } \\
\text { cujos níveis } \\
\text { de } \\
\text { preparação } \\
\text { científica } \\
\text { e/ou teórica } \\
\text { sejam iguais } \\
\text { ou } \\
\text { equivalentes. }\end{array}$ & $\begin{array}{l}\text { - disposição } \\
\text { própria dos parti- } \\
\text { cipantes para o } \\
\text { trabalho inter- } \\
\text { disciplinar; } \\
\text { - comunicação } \\
\text { (troca } \\
\text { intersubjetiva oral } \\
\text { ou escrita, } \\
\text { realizada entre } \\
\text { integrantes da } \\
\text { equipe, em uma } \\
\text { situação ideal de } \\
\text { fala); } \\
\text { - iguais ou } \\
\text { equivalentes } \\
\text { niveis de } \\
\text { preparação } \\
\text { científica com } \\
\text { relação ao tema } \\
\text { em estudo. }\end{array}$ & $\begin{array}{l}\text { - presença de todos } \\
\text { os integrantes nas } \\
\text { reuniōes realizadas } \\
\text { pela equipe } \\
\text { interdisciplinar } \\
\text { estudada; } \\
\text { - participação ativa } \\
\text { dos integrantes da } \\
\text { equipe nas reuniōes } \\
\text { de trabalho; } \\
\text { - contribuição dada } \\
\text { por todos os } \\
\text { integrantes da equipe } \\
\text { com relação ao objeto } \\
\text { de estudo, através de } \\
\text { argumentos racionais } \\
\text { e de base teórica } \\
\text { e/ou técnica para a } \\
\text { discussão efetuada; } \\
\text { - participantes da } \\
\text { equipe } \\
\text { interdisciplinar com } \\
\text { nivel de formação } \\
\text { profissional, no } \\
\text { mínimo, constituído } \\
\text { pela graduação na } \\
\text { área específica; } \\
\text { - presença na equipe } \\
\text { de representantes das } \\
\text { mais diversas áreas } \\
\text { concementes à saúde } \\
\text { (assistentes sociais, } \\
\text { pedagogos, médicos, } \\
\text { sociólogos, } \\
\text { educadores, } \\
\text { psiquiatras, } \\
\text { psicólogos, } \\
\text { enfermeiras...); } \\
\text { - busca de todos os } \\
\text { integrantes da equipe } \\
\text { por um avanço nos } \\
\text { estudos existentes e } \\
\text { relevantes para área } \\
\text { de intervenção à qual } \\
\text { estão envolvidos } \\
\text { enquanto equipe } \\
\text { interdisciplinar; } \\
\text { - reuniões de estudos } \\
\text { sobre questōes } \\
\text { teóricas entre os } \\
\text { integrantes das } \\
\text { equipes } \\
\text { interdisciplinares } \\
\text { estudadas. }\end{array}$ & $\begin{array}{l}\text { - entrevistas } \\
\text { com } \\
\text { integrantes } \\
\text { da equipe } \\
\text { interdisciplinar } \\
\text { estudada; } \\
\text { - observação } \\
\text { de reuniões } \\
\text { de equipe } \\
\text { (reuniōes } \\
\text { técnicas e } \\
\text { teóricas); } \\
\text { - análise das } \\
\text { contribuições } \\
\text { realizadas } \\
\text { pelos } \\
\text { membros da } \\
\text { equipe } \\
\text { interdisciplinar } \\
\text { estudada; } \\
\text { - observaçāo } \\
\text { das áreas } \\
\text { representadas } \\
\text { na } \\
\text { constituição } \\
\text { da equipe } \\
\text { interdisciplinar } \\
\text { estudada. }\end{array}$ \\
\hline
\end{tabular}




\begin{tabular}{|c|c|c|c|c|c|}
\hline HIPÓTESES & CATEGORIAS & CONCEITOS & DIMENSÕES & INDICADORES & $\begin{array}{l}\text { PROCEDI- } \\
\text { MENTOS }\end{array}$ \\
\hline & $\begin{array}{l}\text { situação ideal } \\
\text { de fala }\end{array}$ & $\begin{array}{l}\text { "critério de } \\
\text { uma } \\
\text { argumentação } \\
\text { discursiva } \\
\text { que implica } \\
\text { uma } \\
\text { distribuição } \\
\text { simétrica de } \\
\text { chances de } \\
\text { escolhas e de } \\
\text { realização" } \\
\text { (SIEBENEICH- } \\
\text { LER, 1989, p. } \\
\text { 94) e que } \\
\text { pressuponha } \\
\text { a condição de } \\
\text { aceitação não } \\
\text { coercitiva } \\
\text { sobre } \\
\text { consegüências } \\
\text { e efeitos de } \\
\text { determinadas } \\
\text { decisōes por } \\
\text { parte de } \\
\text { todos os } \\
\text { envolvidos } \\
\text { direta ou } \\
\text { indiretamente } \\
\text { na discussão; } \\
\text { em outras } \\
\text { palavras, } \\
\text { pressuposição } \\
\text { da } \\
\text { concretização } \\
\text { dos principios } \\
\text { U e D da } \\
\text { teoria } \\
\text { habermasiana. }\end{array}$ & $\begin{array}{l}\text { - distribuição } \\
\text { simétrica de } \\
\text { participação de } \\
\text { todos integrantes } \\
\text { da equipe; - } \\
\text { Princípio U } \\
\text { (aceitação não } \\
\text { coercitiva de } \\
\text { todos os } \\
\text { concernidos com } \\
\text { relação às con } \\
\text { sequiências e } \\
\text { efeitos possíveis } \\
\text { a partir de uma } \\
\text { decisão tomada } \\
\text { em processo } \\
\text { conjunto e ético } \\
\text { discursivo); } \\
\text { - Princípio D } \\
\text { (participação de } \\
\text { todos os } \\
\text { concernidos no } \\
\text { discurso } \\
\text { argumentativo e } \\
\text { intersubjetivamentte } \\
\text { realizado). }\end{array}$ & $\begin{array}{l}\text { - consulta a todos os } \\
\text { integrantes da equipe } \\
\text { a respeito de } \\
\text { situaçöes que estão } \\
\text { em discussão (casos, } \\
\text { procedimentos } \\
\text { técnicos, } \\
\text { planejamento de } \\
\text { açōes institucionais e } \\
\text { extra-institucionais...); } \\
\text { - demonstração por } \\
\text { parte dos integrantes } \\
\text { da equipe, durante } \\
\text { processos } \\
\text { argumentativos de } \\
\text { uma mesma ou } \\
\text { equivalente } \\
\text { competência (técnica } \\
\text { e teórica); } \\
\text { - postura } \\
\text { democrática de } \\
\text { receptividade e } \\
\text { respeito por parte de } \\
\text { todos os } \\
\text { componentes da } \\
\text { equipe com relação à } \\
\text { manifestação racional } \\
\text { de um dos } \\
\text { integrantes da } \\
\text { mesma; } \\
\text { - presença das } \\
\text { necessidades e } \\
\text { opiniões dos } \\
\text { elementos não } \\
\text { participantes diretos } \\
\text { da equipe mas } \\
\text { envolvidos nas } \\
\text { conseqüências e } \\
\text { decisōes da mesma, } \\
\text { evidenciados pelo } \\
\text { discurso dos } \\
\text { integrantes do grupo } \\
\text { interdisciplinar } \\
\text { estudado. }\end{array}$ & $\begin{array}{l}\text { - observação } \\
\text { de reuniōes } \\
\text { de equipe; - } \\
\text { entrevistas } \\
\text { com os } \\
\text { integrantes } \\
\text { da equipe } \\
\text { interdisciplinar } \\
\text { estudada. }\end{array}$ \\
\hline
\end{tabular}

Algumas conclusões provisórias já são possiveis de serem apresentadas. Até o presente momento pudemos constatar que, de uma forma geral, a categoria profissional dos assistentes sociais, no Rio Grande do Sul, apresenta um reconhecimento da importância e necessidade de uma postura interdisciplinar frente à atual realidade. Entretanto, no que se refere ao entendimento do que venha a ser esta postura interdisciplinar ainda existe uma forte fragmentação e obscuridade no discurso dos assistentes sociais. 
Associado a estas questões já podemos constatar também uma fragilidade no que se refere a empreendimentos dos próprios Cursos de Graduação em Serviço Social do Rio Grande do Sul e dos próprios órgãos representativos da categoria profissional. Ao serem investigados, pois são objeto da nossa pesquisa, através de um levantamento de dados referentes às ações voltadas à formação profissional numa perspectiva interdisciplinar, demonstraram uma resposta bastante indicativa de um certo distanciamento desta realidade no que se refere à priorização de estudos que dizem respeito a aspectos pertinentes a ações da categoria profissional nos dias atuais.

Evidentemente que a existência destas realidades anteriormente citadas reflete na própria ação comunicativa e interventiva concretizada pelos profissionais junto às diversas áreas do conhecimento, onde constatamos até então que, embora o Serviço Social nas cinco equipes pesquisadas seja reconhecido como área pertinente para efetivação dos trabalhos propostos, seu reconhecimento pelas demais categorias profissionais ainda se deve a uma ação imediatista e de cunho paliativo. Os próprios profissionais reforçam esta percepção ao apresentarem uma fala que prioriza a busca pelo rompimento com essas situações e uma ação que as reproduzem, seus próprios atos contradizem seus discursos numa contradição performativa; logo, os dados colhidos até então e confrontados com nosso instrumental de análise tendem a demonstrar que as ações desses profissionais não estão calcadas e, em determinadas casos, não privilegiam uma ação interdisciplinar. 